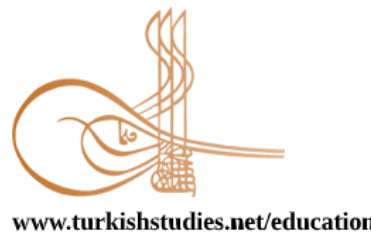

Turkish Studies - Educational Sciences

Research Article / Araştırma Makalesi

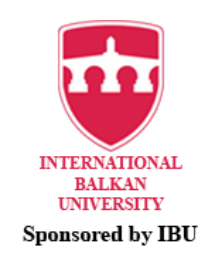

\title{
Müzik Yazılımlarına Yönelik Tutum Ölçeği Geliştirme Çalışması*
}

\author{
A Study on Developing Attitude Scale Towards Music Software
}

\author{
Erkan Demirtaş** $^{* *}$ Sadık Özçelik ${ }^{* * *}$
}

\begin{abstract}
Music software is one of the most important indicators of technological advances in the field of music. Along with the advances in information technologies, the variety of music software has increased significantly, especially with the widespread use of smart phones and their features. Music software suitable for use at all levels from tuning to professional studio recordings make important contributions to musical life. In this study, it was aimed to develop a scale in order to determine attitudes of music students towards music software. A systematic process has been implemented in the development of the scale. While preparing the item pool of the scale, attitude and sub-components (cognitive, affective, behavioral) were taken into consideration. The expressions in the pool of items created were evaluated by the four experts, one in the field of Measurement and Evaluation and one in the field of Turkish Education, and two in the field of Music Education, for scope validity. Expert opinion was applied for the coverage and the 36 items draft scale was applied to a total of 212 music students (bachelor's $n=152$, master's $n=39$ and $\mathrm{Ph} . \mathrm{D} n=21$ ). Implementation of the scale was carried out on a voluntary basis after obtaining permission from the relevant departments. Factor analysis was performed to determine the validity of the structure. As a result of the exploratory factor analysis, it was determined that the scale consists of 2 factors and 17 items. The validity of the obtained attestation was confirmed by confirmatory factor analysis. The Cronbach's alpha reliability coefficient of the scale was .97, while the reliability of the sub-scales was .95 and .97 . As a result of the findings, it was determined that the scale measures the attitudes towards music software in a valid and reliable way.
\end{abstract}

Structured Abstract: The discoveries and advancements in the field of electronics in the 20th century provoked both the appearance of the technologies that are complicated and have multiple functionalities and the use of these technologies in every part of life in the 21 st century. The advancements, especially in the computer and software technologies, caused significant changes in human life. The produced software is used in the field of music, as well, and provide convenience a lot. From tuning to individual instrument practices; from recording music to sharing it; from production to live recordings music software are exploited. The music software, in general, could be classified as notation software, recording and arranging software (DAW), music

\footnotetext{
* Bu çalışmanın veri toplama süreci 2018-2019 eğitim öğretim döneminde ilgili bölüm yönetimlerinden izin alınarak yürütülmüştür.

** Doktora Öğrencisi, Gazi Üniversitesi, Eğitim Bilimleri Enstitüsü, Müzik Eğitimi Bölümü PhD Candidate, Gazi University, Graduate School of Educational Sciences, Division of Music Education ORCID 0000-0002-4357-6697

erkandemirts@gmail.com

**** Prof. Dr., Gazi Üniversitesi, Gazi Eğitim Fakültesi, Müzik Eğitimi Bölümü

Prof. Dr., Faculty of Education, Division of Music Education

ORCID 0000-0001-6243-9957

scelik@gazi.edu.tr
}

Cite as/ Atıf: Demirtaş, E. \& Özçelik, S. (2020). Müzik yazılımlarına yönelik tutum ölçeği geliştirme çalışması. Turkish Studies - Education, 15(3), 1715-1727. https://dx.doi.org/10.29228/TurkishStudies.41731

Received/Geliş: 12 February/Şubat 2020

Accepted/Kabul: 20 June/Haziran 2020

Checked by plagiarism software

Copyright (C) INTAC LTD, Turkey

Published/Yayın: 25 une/Haziran 2020

CC BY-NC 4.0 
training software, and auxiliary software. Besides their various uses, music software is used in the field of music education. The utilization of music software in instrumental teaching studies, theory practices, and ear training contributes positively.

The attitude of individuals towards music software is a valuable parameter in the utilization of music software both for the purpose of personal development and in the field of education. Thurstone (1928) defined attitude as "the accumulation of human tendencies, emotion, prejudice, belief and sensations" (p. 531), while İnceoğlu (2010) defined as "a cognitive, affective and behavioral reaction which the humankind organize based on the motivations and knowledge towards himself or a social matter, object, and an incident" (p. 13). Attitude is composed of three sub-components; cognitive, affective and behavioral. An attitude towards an object could affect the manner, behavior, and preference of an individual towards that object. In this sense, the designation of attitudes towards music software could be interpreted as an indicator of how the participators side with music software.

\section{Method}

This work is a scale development study. 212 current students pursuing bachelor's, master's and Ph.D. degrees at Music Education Department of Gazi University and Turkish Music State Conservatory of Hac1 Bayram Veli University constitute the study group of the research. Of the participators, \%59.9 is female and $\% 40.1$ is male. When the study group was formed, the criteria of being a music student and a volunteer was taken into consideration. In the research, for the purpose of identifying the validity of The Scale of Attitude Towards Music Softwares, structure and scope validities were analyzed. Scope validity has been determined, taking the opinions of four experts.

To identify the structural validity of the scale, Exploratory Factor Analysis (EFA) and Confirmatory Factor Analysis (CFA) are applied. For EFA, SPSS 25 package software has been used. Before applying EFA, the data is checked whether it is suitable or not for factor analysis. For that, Kaiser-Meyer Olkin (KMO) and Bartlett Sphericity tests are benefitted. After determining the suitability of the data for factor analysis, EFA has been executed using Promax rotation technique and principal component analysis to identify the structural validity of the scale.

As a result of EFA, how many factors the scale is composed of and beneath which factors the scale items gather have been determined. DFA has been executed to test the structure put forth by EFA. For CFA, LISREL 8.8 package software has been benefitted. Analyzing the adaptation and error indexes, which were attained as a result of CFA, the structure emerged in the scale has been evaluated. To identify the reliability of the scale, Cronbach alpha coefficient of reliability has been calculated. Cronbach alpha coefficient of reliability has been evaluated, calculating for the whole scale and the sub-factors.

\section{Result and Suggestions}

For scope validity, an analysis has been carried out by four experts and after that, an eventual trial form, which is composed of 36 statements, has been created. To put forth the construct validity, exploratory and confirmatory factor analysis has been conducted. As a result of the exploratory factor analysis executed applying SPSS package software, a scale model, which reveals sub-dimensions and the items related to subdimensions, has been put forth.

As a result of EFA, a structure which is composed of 17 articles, which explains the $\% 75.85$ of the total variance, and 2 factors has been attained. There are 11 articles in the first factor, named as positive sensation component and explaining \%68.05 of the variance; and 6 articles in the second factor, named as negative sensation component and explaining $\% 7.79$ of the variance. The accuracy of the model created has been tested applying CFA. When the adaptation index values, which are handled in the evaluation of the model, are analyzed, a harmony between model structure and the data at an acceptable level has been detected. In the item analysis studies, the item-total correlation has been checked. The finding of that scale items both served to scale the feature that is intended to be scaled and distinguished the individuals that possess or do not possess the feature that is to scale has been reached.

For reliability studies, the Cronbach alpha coefficient of reliability that belongs to the scale. The coefficient of reliability that belongs the whole scale is calculated as .97 ; the coefficient of reliability for the first factor as .95 and for the second factor as .97 . When the reliability results are analyzed, it is observed that 
the scale is reliable both on the whole and at the factorial level. Accordingly, it could be said that the scale items served its purpose to scale the feature intended to be scaled.

When the findings attained in the study are evaluated en masse, it could be said that the scale developed to measure the attitudes towards the music software possess viable qualifications. It is thought that the scale developed will be an effective data gathering tool in presenting the attitudes of the music students towards music software. Lacking a scale intended for identifying the attitudes towards music software, it is thought that this scale that is developed will become a significant reference with regard to future studies. Consequently, it could be said that a valid and reliable scale at an acceptable level has been developed.

It could be stated that high points reached when the scale is applied signifies the positive attitudes towards music software. This scale could be used in identifying the attitudes of the other music students stayed out of the study, music teachers and academics working in music departments towards music software. Due to [the limited] time and financial possibilities, the validity and reliability studies have been conducted on the same sample of respondents. In future studies, the validity and reliability values could be tested on different study groups. Broadening the scope of the scale, the researchers interested in the subject could plan various studies regarding the implementations of the scale.

Keywords: Education Sciences, Music Education, Music Software, Scale Development, Attitude.

Öz: Müzik yazılımları teknolojik ilerlemelerin müzik alanındaki en önemli göstergelerindendir. Bilişim teknolojilerindeki ilerlemelerle beraber özellikle akıllı telefonların yaygınlaşması ve özelliklerinin artmasıyla müzik yazılımları çeşitliliği de önemli derecede artmıştır. Akort yapmaktan, profesyonel stüdyo kayıtlarına kadar her seviyede kullanıma uygun müzik yazılımları, müzikal hayata önemli katkılar sağlamaktadır. Bu çalışmada, müzik öğrencilerinin müzik yazılımlarına yönelik tutumlarını belirleyebilmek için bir ölçek geliştirilmesi amaçlanmıştır. Ölçeğin geliştirilmesinde sistematik bir işlem süreci uygulanmıştır. Ölçeğe ait madde havuzu hazırlanırken tutum ve alt bileşenler (bilişsel, duyuşsal, davranışsal) dikkate alınmıştır. Oluşturulan madde havuzundaki ifadeler kapsam geçerliği için, Ölçme ve Değerlendirme alanı ve Türkçe Eğitimi alanından bir, Müzik Eğitimi alanından iki olmak üzere dört uzman tarafından değerlendirilmiştir. Uzman görüşleri doğrultusunda 36 maddelik taslak ölçek formu oluşturulmuştur. Hazırlanan taslak ölçek formu Gazi Üniversitesi Müzik Eğitimi Anabilim Dalı ve Hacı Bayram Veli Üniversitesi Türk Müziği Devlet Konservatuvarında öğrenimine devam eden lisans $(n=152)$, yüksek lisans $(n=39)$, ve doktora $(n=21)$ öğrencisi toplam 212 müzik öğrencisine uygulanmıştır. Ölçek uygulaması ilgili bölüm başkanlıklarından izin alınmasının ardından gönüllük esasına göre gerçekleştirilmiştir. Yapı geçerliğini ortaya koymak için faktör analizi yapılmıştır. Uygulanan açımlayıcı faktör analizi sonucunda ölçeğin 2 faktör ve 17 maddeden oluştuğu tespit edilmiştir. Oluşturulan yapının geçerliği doğrulayıcı faktör analizi uygulanarak kontrol edilmiştir. Ölçeğin bütününe ait Cronbach alfa güvenirlik katsayısı .97 iken alt faktörlerin güvenirlik katsayıs1 .95 ve .97 olarak tespit edilmiştir. Elde edilen bulgular sonucunda ölçeğin müzik yazılımlarına yönelik tutumları geçerli ve güvenilir şekilde ölçtüğü tespit edilmiştir.

Anahtar Kelimeler: Eğitim Bilimleri, Müzik Eğitimi, Müzik Yazılımları, Ölçek Geliştirme, Tutum.

\section{Giriş}

Yirminci yüzyılda elektronik alanındaki keşifler ve ilerlemeler, yirmibirinci yüzyılda karmaşık ve çoklu işlevselliğe sahip teknolojilerin ortaya çıkmasına ve hayatın her alanında bu teknolojilerin kullanılmasına sebep olmuştur (Güler, Şahinkayası \& Şahinkayası, 2017). Özellikle bilgisayar teknolojilerinin gelişimi ve yaygınlaşması insan hayatında şimdiye kadar görülmemiş hızda ve önemde değişikliklere yol açmıştır. Bilgisayar teknolojilerinin yaygınlaşma sebebinin bu cihazlar için üretilen yazılımların sağladıkları büyük kolaylıklar olduğu söylenebilir. Yazılım genel olarak, bir bilgisayar sisteminin çalışması, yönetilmesi veya bilgisayarda bir işin yapılması amacı ile oluşturulan programlar veya kısaca problem ile çözüm arasında bir ara yüz olarak tanımlanabilir (Keskinkılıç \& Özmen, 2018). Mobil bilişim teknolojilerinin de devreye girmesinin ardından her gün her alanla ilgili çok sayıda yazılım üretilmektedir. 
Üretilen yazılımlar müzik alanında da çeşitli amaçlar için kullanılmakta ve bir çok kolaylık sağlamaktadır. Akort yapmaktan, bireysel çalgı çalışmalarına; müziğin kayıt aşamasından, paylaşılmasına; eser üretmekten, profesyonel canlı performanslara kadar birçok amaç için müzik yazılımları kullanılmaktadır. Genel olarak müzik yazılımları; nota yazım programları, ses kayıt ve düzenleme programları, müzik eğitimi yazılımları ve yardımcı yazılımlar olarak sınıflandırılabilir (Eroğlu \& Demirtaş, 2018).

Müzik yazılımları çeşitli kullanım amaçlarının yanında müzik eğitimi alanında da kullanılmaktadır. Enstrüman eğitimi çalışmalarında (Lehimler, 2012; Juntunen, Ruokonen \& Ruismäki, 2015), teori çalışmalarında (Wise, Greenwood \& Davis, 2011; Şen, 2011; Ahmetzade, 2013), kulak eğitimi çalışmalarında (Miller, 2012) müzik yazılımlarının kullanımı olumlu yönde katkılar sağlamaktadır. Bu sebeplerle müzik yazılımları kullanımı müzik öğretmenliği meslek becerilerinden birisi haline gelmiştir (Lehimler, 2019).

Müzik yazılımlarının, hem bireysel gelişim amaçlı hem de eğitim-öğretim alanı içinde benimsenerek kullanılmasında, bireylerin müzik yazılımlarına yönelik tutumları da önemli bir etkendir. Tutum "tutulan yol, tavır" anlamına gelmektedir (TDK). Tutumla ilgili alanyazında birçok tanımlama bulunmaktadır. Thurstone (1928) "insanın bir konu hakkındaki eğilimlerinin, duygularının, önyargılarının, inançlarının ve hislerinin toplamı" (s. 531); Allport (1935) "bireyin belirli bir objeye veya bir kimseye karşı zihinsel açıdan hazır oluş durumu veya belirli bir şekilde tavır alışı" (Akt, Çetin \& Çetin, 2019, s. 142); Sanford (1961) "bir nesneye olumlu veya olumsuz tepki göstermeye hazırlık durumu" (Akt, Tavşancıl, 2014, s. 66); İnceoğlu (2010) "bireyin kendine ya da çevresindeki herhangi bir nesne, toplumsal konu ya da olaya karşı deneyim, bilgi duygu ve güdülerine dayanarak örgütlediği zihinsel, duygusal ve davranışsal bir tepki ön eğilim” (s. 13) olarak tutumu tanımlamışlardır. Tutum genel olarak üç alt bileşenden oluşmaktadır bunlar; bilişsel, duyuşsal ve davranışsal bileşenlerdir. Bir nesneye yönelik tutum, bireyin o nesneye karşı tavrını, davranışını ve tercihini etkileyebilmektedir. Bu bağlamda müzik yazılımlarına yönelik tutumların belirlenmesi, katılımcıların profesyonel hayatlarında müzik yazılımlarını kullanma eğilimlerinin ve tercihlerinin belirlenmesi için bir gösterge olarak değerlendirilebilir.

Araştırmacıların ölçmek istediği özelliği iyi tanımlamaları ve buna uygun olarak maddeleri açık bir şekilde ifade etmeleri ölçek geliştirme çalışmaları için önem arz etmektedir. Bu amaçla alanyazın incelenerek ölçme aracı için gerekli olan müzik yazılımlarının özellikleri araştırılmıştır. Alanyazın incelendiğinde müzik yazılımlarına yönelik tutumun ölçüldüğü bir çalışma tespit edilememiştir. Müzik yazılımları, teknoloji ve tutum ile ilgili yapılan ulusal ve uluslararası araştırmalar incelenerek geliştirilecek ölçekle ilgili madde özellikleri belirlenmeye çalışılmıştır. Müzik eğitiminde teknoloji kullanılmasıyla ilgili (Çakırer, 2002; Koç, 2004; Koldemir, 2008; Beşer, 2010; Babacan \& Babacan, 2011; Şen, 2011; Wise, Greenwood \& Davis, 2011; Çevik \& Alkan, 2012; Dammers, 2012; Lehimler, 2012; Yengin, 2014; Bell, 2015; Juntunen, Ruokonen \& Ruismaki, 2015; Order, 2015; Önder \& Y1ld1z, 2015; Demirtaş, 2017; Lehimler, 2019) ve teknoloji ve tutum ile ilgili (Ledger, 1999; Yavuz, 2005; Arslan, 2006; Ekici \& Bahçeci, 2006; Van Laarhoven \& Conderman, 2011; Kenar, 2012; Cabi, 2016;) bazı çalışmalar incelenen araştırmalara örnek olarak gösterilebilir. Bu çalışmada müzik yazılımlarına yönelik tutumların ölçülebilmesi için bir ölçek geliştirilmesi hedeflenmiştir ve bu amaçla sistematik bir işlem süreci izlenmiştir. Ortaya çıkan ölçeğin müzik yazılımlarına yönelik tutumları ölçmek isteyen araştırmacılar için faydalı olacağ 1 düşünülmektedir.

\section{Yöntem}

$\mathrm{Bu}$ çalışma, bir ölçek geliştirme çalışması olarak yürütülmüştür. Müzik Yazılımlarına Yönelik Tutum Ölçeği geliştirilme çalışmasının hangi aşamalarda gerçekleştirildiği ve çalışma grubunun özellikleri aşağıda sırasıyla sunulmuştur. 


\section{Çalışma Grubu}

Araştırmanın çalışma grubunu, Gazi Üniversitesi Müzik Eğitimi Anabilim Dalı ve Hacı Bayram Veli Üniversitesi Türk Müziği Devlet Konservatuvarında öğrenimine devam eden lisans $(n=152)$, yüksek lisans $(n=39)$, ve doktora $(n=21)$ öğrencisi toplam 212 müzik öğrencisi oluşturmaktadır. Katılımcıların \%59.9'u (n=127) kadın ve \%40.1'i $(n=85)$ erkektir. Çalışma grubu belirlenirken müzik öğrencisi olma ve gönüllü olma ölçütleri dikkate alınmıştır. Çalışma grubuna ait dağ 1 lım Tablo 1'de gösterilmiştir.

Tablo 1: Çalışma Grubu

\begin{tabular}{lccc}
\hline & Gazi Üniversitesi & Hacı Bayram Veli Üniversitesi & Toplam \\
\hline Lisans & 108 & 44 & 152 \\
\hline Yüksek Lisans & 27 & 12 & 39 \\
\hline Doktora & 18 & 3 & 21 \\
\hline Toplam & 124 & 88 & 212 \\
\hline
\end{tabular}

\section{Ölçeğin Geliştirilme Süreci}

Müzik Yazılımlarına Yönelik Tutum Ölçeği'nin geliştirilme çalışması için öncelikle alanyazın taraması yapılmıştır. Araştırmalar incelenerek ölçekte kullanılabilecek ifadelerin neler olabileceği tespit edilmiştir. Ölçeğe ait madde havuzu hazırlanırken tutum ve alt bileşenler (bilişsel, duyuşsal, davranışsal) dikkate alınmıştır. Bilişsel bileşene ait 12, duyuşsal bileşene ait 14 ve davranışsal bileşene ait 12 olmak üzere toplam 38 ifadeden oluşan madde havuzu hazırlanmıştır. Oluşturulan madde havuzundaki ifadeler kapsam geçerliği için, Ölçme ve Değerlendirme alanı ve Türkçe Eğitimi alanından bir, Müzik Eğitimi alanından iki olmak üzere dört uzman tarafindan değerlendirilmiştir. Uzman görüşleri sonucunda, anlaşılır olmadığ 1 ve birden fazla yargi içerdiği tespit edilen 8 ifade düzeltilmiş, görüşler doğrultusunda tutum ölçmek için uygun görülmeyen 2 ifade ise ölçekten çıkartılmıştır. Sonuç olarak 36 ifadeden oluşan nihai deneme formu oluşturulmuştur. İfadelerin 21 'i olumlu, 15 ' $\mathrm{i}$ ise olumsuz yarg 1 içermektedir. Katılımcıların ölçekteki ifadelere katılım düzeylerini belirlemek için Likert (1932) tipi beşli derecelendirme ölçeği (1 hiç katılmıorum, 2 katılmıyorum, 3 kararsızım, 4 katılıyorum, 5 tamamen katılıyorum) kullanılmışıır.

\section{Verilerin Toplanması}

Oluşturulan ölçek formunun çalışması, araştırmacının uygulama ortamlarına giderek (Gazi Üniversitesi Müzik Eğitimi Anabilim Dalı ve Hacı Bayram Veli Üniversitesi Türk Müziği Devlet Konservatuvarı) ölçekleri doğrudan kendisinin uygulamasıyla gerçekleştirilmiştir. Uygulama öncesi araştırmacı tarafından ön bilgilendirme yapıldıktan sonra katılımcıların ölçeği doldurmaları istenmiştir. Yaklaşık iki ay süren çalışma sonrasında 212 müzik öğrencisi ile ölçek çalışması gerçekleştirilmiştir.

\section{Verilerin Analizi}

Elde edilen verilerin analizinden önce, doldurulan ölçeklerdeki $(n=212)$ eksik, uç ve hatalı değerler incelenmiştir. Analizlere başlanmadan önce, olumsuz olarak yazılmış ifadelere ait puanlar ters çevrilerek tekrar puanlanmıştır. Bu aşamaların ardından çalışmaya ait geçerlik ve güvenirlik analizleri yapılmıştır.

Müzik Yazılımlarına Yönelik Tutum Ölçeği'nin geçerliliğinin saptanması için, kapsam ve yapı geçerlilikleri incelenmiştir. Kapsam geçerliliği dört uzmanın görüşleri alınarak belirlenmiştir. Yapı geçerliliğinin saptanması için ise Açımlayıcı Faktör Analizi (AFA) ve Doğrulayıcı Faktör Analizi (DFA) uygulanmıştır. AFA için SPSS (Statistical Package for the Social Sciences) 25 paket programı kullanılmıştır. AFA uygulanmasından önce, verilerin faktör analizi için uygunluğu Kaiser- 
Meyer Olkin (KMO) ve Bartlett Sphericity testleriyle incelenmiştir. Verilerin faktör analizine uygunluğu saptandıktan sonra, temel bileşenler analizi ve promax döndürme tekniği kullanılarak AFA uygulanmıştır. Analiz sonucunda, ölçeğe ait faktörler ve faktörlere ait ölçek maddelerinin hangileri olduğu saptanmıştır. AFA ile belirlenen yapının uygunluğu DFA ile test edilmiştir. DFA için LISREL 8.8 paket programı kullanılmıştır. DFA sonucunda bulunan uyum ve hata indeksleri incelenerek, AFA ile ortaya çıkarılan yapı değerlendirilmiştir. Ölçeğin güvenirliğinin belirlenmesi için, Cronbach alfa güvenirlik katsayısı ölçeğin tamamı ve alt faktörler için hesaplanarak incelenmiştir.

\section{Bulgular}

$\mathrm{Bu}$ bölümde Müzik Yazılımlarına Yönelik Tutum Ölçeği'nin geçerlik ve güvenirliğine ilişkin bulgulara yer verilmiştir.

\section{Geçerliğe İlişkin Bulgular}

Ölçek geliştirme çalışmalarında faktör analizinin yapılabilmesi için, ulaşılacak katılımcı sayısının, hazırlanan madde sayısından 5-10 katı kadar büyük olması gerektiği alanyazında belirtilmektedir (Kass \& Tinsley, 1979; Kline, 1994; Bryman \& Cramer, 2001; Tavşanc1l, 2014). Araştırmada bu ölçüt göz önüne alınarak 212 katılımcının verileri üzerinden AFA uygulanmıştır.

Faktör analizine başlamadan önce verilerin uygunluğunu saptamak için Kaiser-Meyer Olkin (KMO) katsayısı hesaplanmış ve Bartlett Sphericity Testi yapılmıştır. KMO değeri 91 olarak hesaplanmıştır. Kaiser (1974) KMO değerinin 0.5 'ten büyük olması gerektiğini, Field (2005) ise 0.6 'dan büyük olması gerektiğini belirtmiştir. Bu durumda gözlenen KMO değerinin (.91) istenen KMO değerinden yüksek olduğu belirlenmiştir. Bartlett Sphericity testi ise, verilerin çok değişkenli normal dağılımdan gelip gelmediğinin incelendiği bir test olarak kullanılmaktadır. Uygulanan Bartlett Sphericity testine göre bulunan istatistiksel sonucun anlamlı olduğu saptanmıştır $(\mathrm{x} 2=12818,451, \mathrm{p}=0.00)$. Elde edilen bu bulgulara göre, hazırlanan ölçeğin faktör analizi çalışmas1 yapmak için uygun olduğu söylenebilir.

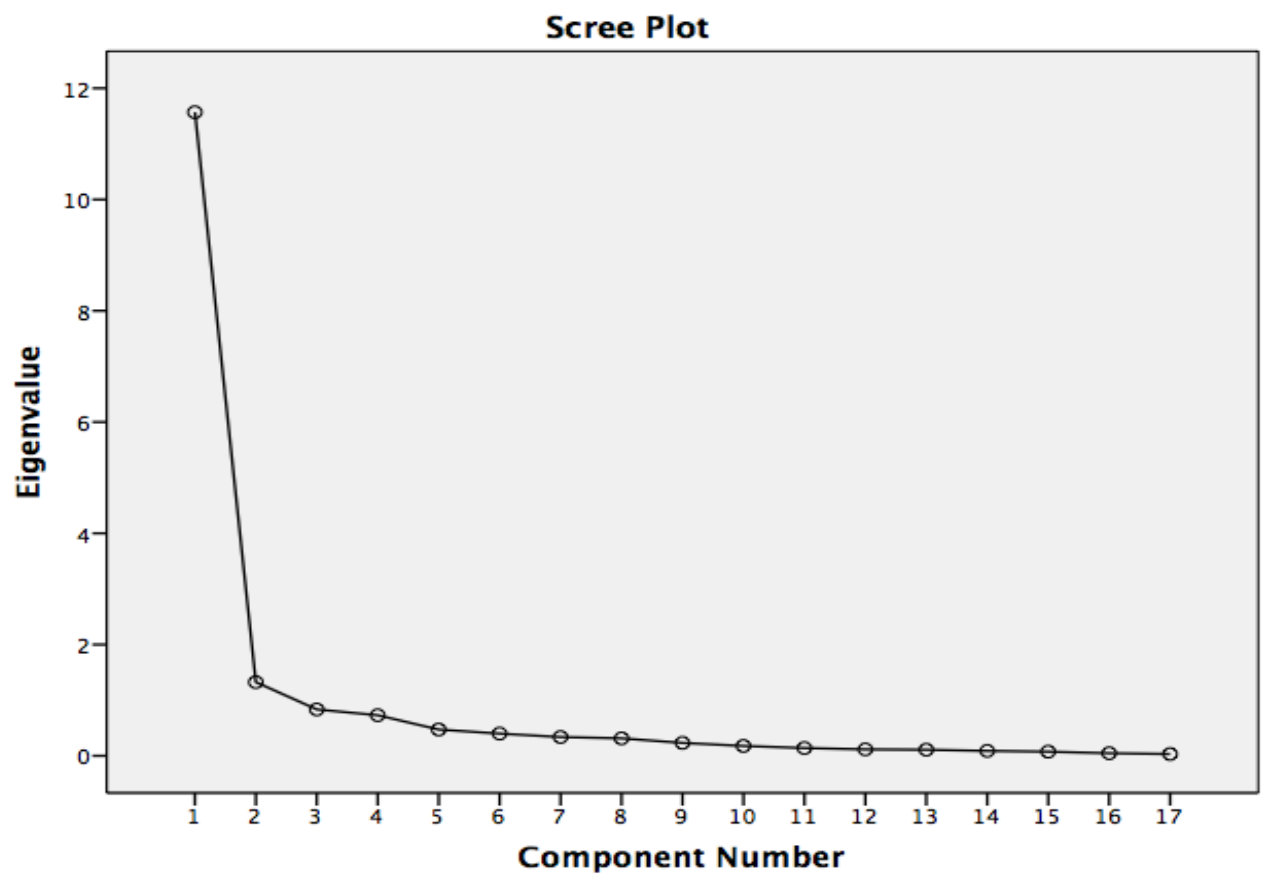

Şekil 1. Scree Plot Grafiği

Turkish Studies - Education, 15(3) 
AFA sonucunda ölçek maddelerinin özdeğeri 1'den yüksek olan 2 faktör altında toplandığ 1 görülmüştür (Şekil 1). Bu iki faktörün ölçeğe ait açıkladıkları varyans ise \%75.8 olarak tespit edilmiştir. Madde faktör yükleri incelendiğinde hiç bir faktöre yük vermeyen (.30'un altı) ve iki faktöre birden yük veren maddeler ölçekten teker teker çıkartılarak işlem tekrarlanmıştır. Tablo 2'de ölçek maddeleri, faktörler ve faktör yükleri gösterilmiştir.

Tablo 2: Müzik Yazılımlarına Yönelik Tutum Ölçeği AFA Sonuçları

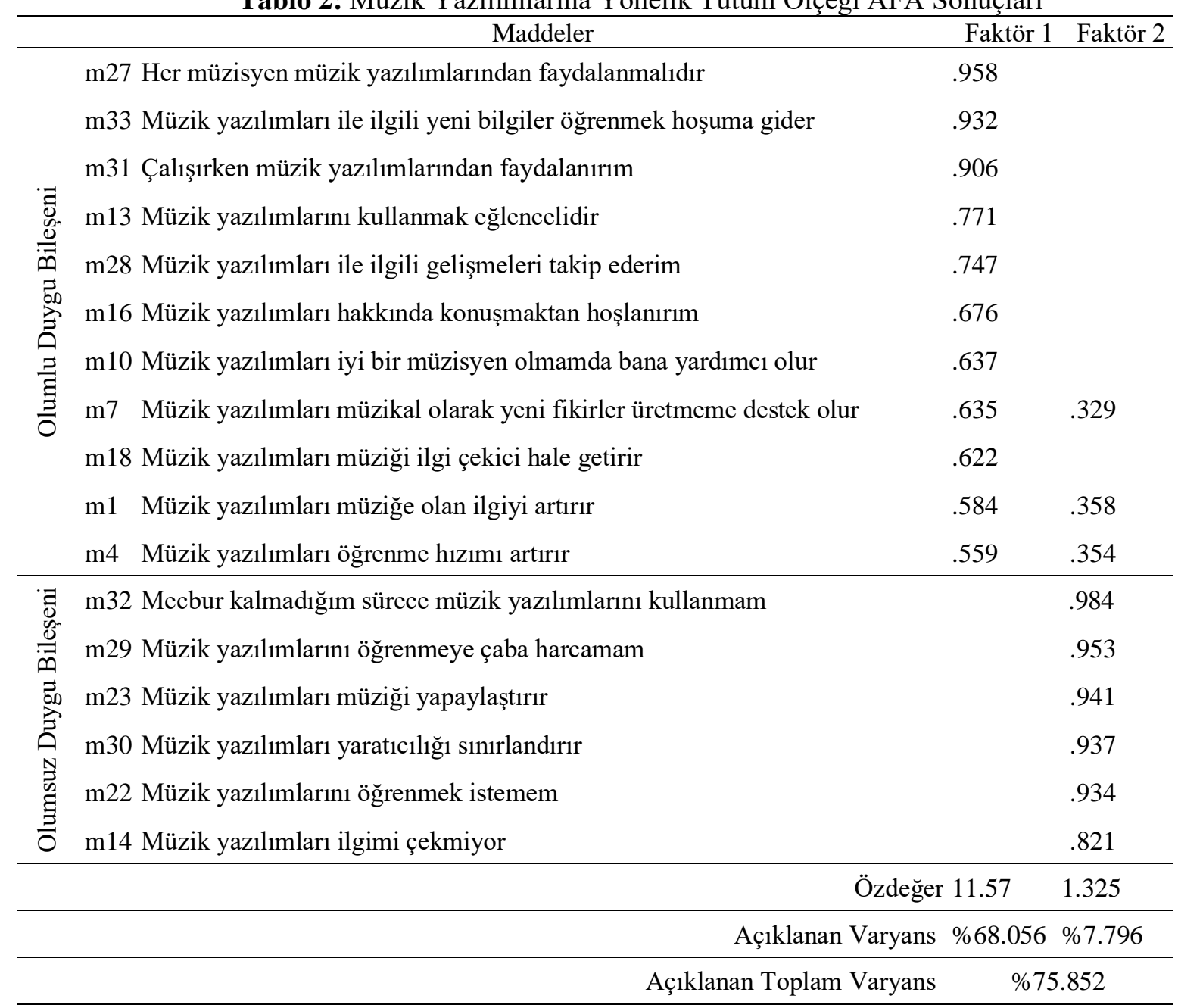

Extraction Method: Principal Component Analysis.

Rotation Method: Promax with Kaiser Normalization.

a. Rotation converged in 3 iterations.

Faktör analizinde bir maddenin bir faktörde gösterilebilmesi için yük değerinin en az .40 olması gerekmektedir (Field, 2005). Tablo 1'de görüldüğü üzere birinci boyut faktör yük değerleri .55 ile .95 arasında değişen 11 maddeden; ikinci faktör yük değerleri .82 ile .98 arasında değişen 6 maddeden oluşmaktadır. İki faktörün toplam varyansın \% 75,85'ini açıkladığı görülmektedir. Toplam varyansın \%68.05'ini açılayan birinci faktör "olumlu duygu bileşeni", toplam varyansın \% 7.79 'unu açıklayan ikinci faktör "olumsuz duygu bileşeni" olarak adlandırılmıştır.

Açımlayıcı faktör analizi sonucunda ortaya çıkan modelin, yapı geçerliğini değerlendirmek için doğrulayıcı faktör analizi (DFA) yapılmıştır. Bunun için; $\chi^{2 / d f}$ (Chi-Square/Degree of Freedom), 
NFI (Normed Fit Index), CFI (Comparative Fit Index), RMSEA (Root Mean Square Error of Approximation), AGFI (Adjusted Goodness of Fit Index), GFI (Goodness of Fit Index), IFI (Incremental Fit Index) ve SRMR (Standardized Root Mean Square Residual) model indeksleri incelenmiştir. AFA ile 17 madde ve 2 faktörden oluştuğu belirlenen ölçek yapısının değerlendirildiği DFA sonucunda, herhangi bir modifikasyon işlemi gerçekleştirilmeden elde edilen sonuçlar şöyledir: $\chi^{2 / \mathrm{df}}=3.52 ; \mathrm{NFI}=0.93 ; \mathrm{CFI}=0.94 ; \mathrm{RMSEA}=0.15 ; \mathrm{AGFI}=0.59 ; \mathrm{GFI}=0.68 ; \mathrm{IFI}=0.94 ; \mathrm{SRMR}=0.054$.

Analiz sonucunda ortaya çıkan modifikasyon önerileri incelendiğinde; m1-m4; m7-m10; m13-m16; m13-m18; m27-m28; m31-m33; m31-m29; m29-m30; m29-m32; m30-m32 maddeleri arasında modifikasyon önerilerinin olduğu görülmüştür. Kuramsal olarak bakıldığında bu maddelerin benzer durumları ölçtükleri ve bu sebeple maddeler arası gizil bir ilişkinin kabul edilebilir olabileceği görülmüş ve öneriler dikkate alınmıştır. Modifikasyon işlemleri gerçekleştirildikten sonra elde edilen sonuçlar şöyledir: $\chi^{2 / d f}=1.62$; NFI=0.97; CFI=0.99; RMSEA=0.07; AGFI=0.83; $\mathrm{GFI}=0.89 ; \mathrm{IFI}=0.99 ; \mathrm{SRMR}=0.034$.

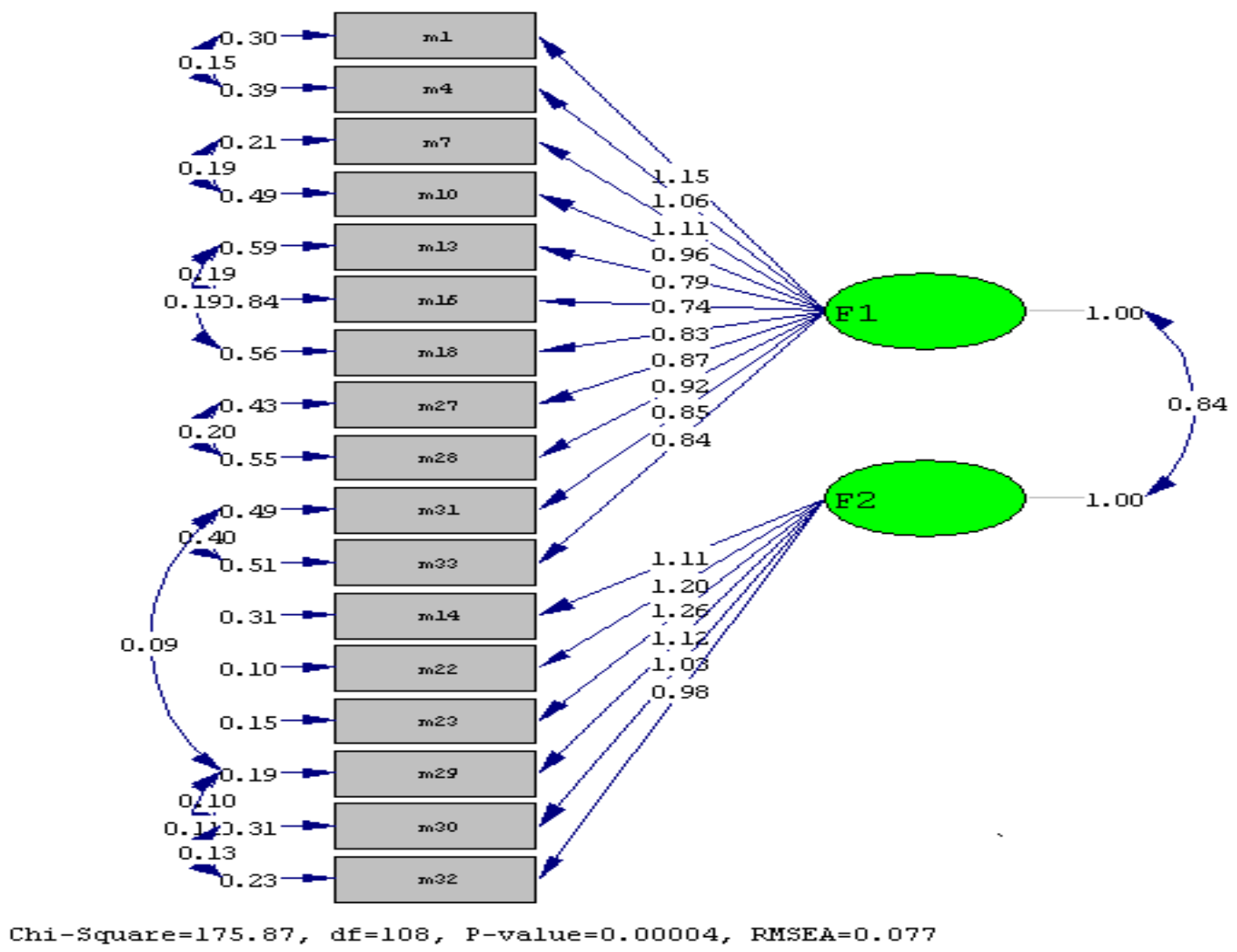

Şekil 2. DFA Sonuçları

DFA sonucunda elde edilen modele ilişkin uyum indeks değerleri incelendiğinde Ki- Kare değerinin serbestlik derecesine oranının 1.62 olduğu tespit edilmiştir. Ki- Kare değerinin 2 veya daha altında çıktığı modellerde mükemmel uyum olduğu değerlendirilmektedir (Kline, 2010). NFI ve CFI değerleri incelendiğinde, iki değerinde .95 değerinden büyük olması mükemmel uyuma sahip olduğunu göstermektedir (Thompson, 2004). RMSEA değeri 0.07 olarak bulunmuştur. Bu değere göre model kabul edilebilir bir uyum değerine sahiptir (Brown, 2006). AGFI ve GFI değerlerinin 90 ve üzerinde olması mükemmel; AGFI için .80 ve GFI için .85 ve üzeri değerlerinin kabul edilebilir uyumu gösterdiği belirtilmektedir (Jöreskog \& Sörborn, 1993). Buna göre AGFI ve GFI için modelin 
uyumunun kabul edilebilir olduğu söylenebilir. Elde edilen IFI değerinin de kabul edilebilir uyum düzeyinde olduğu tespit edilmiştir (Bollen, 1989). SRMR değerinin .05 değerinden küçük çıkması iyi uyuma sahip olduğunu göstermektedir (Byrne, 1998; Diamantopoulos \& Siguaw, 2000).

Oluşturulan ölçeğin her bir maddesinin standardize çözümleme değerlerinin anlamlılık düzeyleri DFA analizinde elde edilen t değerleri ile kontrol edilmiştir. Analiz sonucunda elde edilen t değerlerinin 7.01 ile 13.55 arasında değiştiği belirlenmiştir. Buna göre t değerleri bütün maddeler için $\mathrm{p}<.01$ düzeyinde anlamlı bulunmuştur.

\section{Güvenirlik ve Madde Analizine Yönelik Bulgular}

Oluşturulan ölçeğin güvenirliğini belirlemek için hem ölçek geneli hem de alt boyutları için Cronbach alfa iç tutarlık kat sayıları incelenmiş̧ir. Ayrıca ölçekte yer alan bütün maddelere $(n=17)$ ilişkin olarak, ölçmek için hazırlandığı özelliği ölçüp ölçmediğinin saptanması için madde-toplam korelasyonlarına bakılmıştır. Tablo 3'de güvenirliğe ilişkin bulunan madde-toplam korelasyon değerleri ve Cronbach alfa güvenirlik katsayıları özetlenmiştir.

Tablo 3: Madde-Toplam Korelasyon Değerleri ve Cronbach Alfa Güvenirlik Katsay1ları

\begin{tabular}{|c|c|c|c|}
\hline Faktörler / Maddeler & $\bar{x}$ & $\begin{array}{c}\text { Madde-Toplam } \\
\text { Korelasyonu }\end{array}$ & $\begin{array}{c}\text { Madde Çıkarıldığında } \\
\text { Cronbach Alfa Güvenirlik } \\
\text { Katsayısı }\end{array}$ \\
\hline \multicolumn{4}{|l|}{ Faktör 1} \\
\hline \multicolumn{4}{|c|}{ Olumlu Duygu Bileşeni $(\alpha=.95)$} \\
\hline $\mathrm{m} 1$ & 4,05 & ,860 & ,968 \\
\hline $\mathrm{m} 4$ & 4,00 & ,832 & ,968 \\
\hline m7 & 3,88 & 885 & ,967 \\
\hline $\mathrm{m} 10$ & 3,71 & ,765 & ,969 \\
\hline $\mathrm{m} 13$ & 3,48 & ,713 & ,970 \\
\hline $\mathrm{m} 16$ & 3,38 & ,624 & ,971 \\
\hline $\mathrm{m} 18$ & 3,48 & ,758 & ,969 \\
\hline $\mathrm{m} 27$ & 3,66 & ,765 & ,969 \\
\hline $\mathrm{m} 28$ & 3,78 & ,774 & ,969 \\
\hline $\mathrm{m} 31$ & 3,81 & ,757 & ,969 \\
\hline m33 & 3,79 & ,755 & ,969 \\
\hline \multicolumn{4}{|c|}{ Faktör 2} \\
\hline \multicolumn{4}{|c|}{ Olumsuz Duygu Bileşeni $(\alpha=.97)$} \\
\hline $\mathrm{m} 14 \mathrm{n}$ & 3,85 & ,831 & 968, \\
\hline $\mathrm{m} 22 \mathrm{n}$ & 3,74 & ,868 & ,967 \\
\hline $\mathrm{m} 23 \mathrm{n}$ & 3,73 & ,866 & ,968 \\
\hline $\mathrm{m} 29 \mathrm{n}$ & 3,78 & ,862 & 968 \\
\hline m30n & 3,79 & ,829 & ,968 \\
\hline $\mathrm{m} 32 \mathrm{n}$ & 3,83 &, 824 & ,968 \\
\hline
\end{tabular}

Ölçeğin geneline ait Cronbach alfa güvenirlik katsayıs1 .97 olarak belirlenmiştir. Alt boyutlar düzeyinde güvenirlik katsayıları ise birinci faktör (olumlu duygu bileşeni) için .95 ve ikinci faktör (olumsuz duygu bileşeni) için .97 olarak hesaplanmıştır. Nunnally (1978) güvenirlik katsayısının .70 ve üzerinde çıkmasının güvenirlik için yeterli olduğunu belirtmektedir. Buna göre hesaplanan güvenirlik katsayılarının, ölçeğin kabul edilebilir düzeyde güvenli olduğunu desteklediği söylenebilir.

Oluşturulan ölçekte yer alan 17 maddenin ölçülmek istenen özelliği ölçüp ölçmediği ve ölçülmek istenen özelliğe sahip olan bireylerle olmayanları ayırt edip etmediği incelenmiştir. $\mathrm{Bu}$ amaçla Tablo 2'de verilmiş olan madde analizi sonuçları incelenmiştir. Olumlu duygu bileşeni faktöründe madde-toplam test korelasyonu değerleri .62 ile .88 arasında; olumsuz duygu bileşeni 
faktöründe ise .82 ile .86 arasında değişim gösterdiği tespit edilmiştir. Madde-toplam test korelasyonlarının .30 ve üzerinde olarak hesaplanması maddelerin geçerli olduğunu göstermektedir (Nunnally \& Bernstein, 1994). Elde edilen sonuçlara göre ölçekte yer alan 17 maddenin ölçülmek istenen özelliği ölçtüğü söylenebilir.

\section{Sonuç ve Öneriler}

$\mathrm{Bu}$ çalışmada, müzik yazılımlarına yönelik tutumları belirleyebilmek için geçerli ve güvenilir bir ölçek geliştirilmesi hedeflenmiştir. Çalışma grubu, Gazi Üniversitesi Müzik Eğitimi Anabilim Dalı ve Hacı Bayram Veli Üniversitesi Türk Müziği Devlet Konservatuvarında öğrenimine devam eden ( $\mathrm{n}=212)$ öğrencilerden oluşturulmuştur. Müzik Yazılımlarına Yönelik Tutum Ölçeği'ni geliştirebilmek amacıyla, öncelikle konuyla ilgili alanyazın taraması yapılmış ve ölçekte yer almasının uygun olduğu düşünülen 38 ifadeden oluşan taslak form 5'li Likert tipinde derecelendirilerek oluşturulmuştur.

Ölçek kapsam geçerliği için dört alan uzmanı tarafından incelenmiş ve yapılan inceleme sonrasında 36 ifadeden oluşan nihai deneme formu oluşturulmuştur. Yapı geçerliğini belirleyebilmek için Açımlayıcı ve Doğrulayıcı Faktör Analizi yapılmıştır. SPSS paket programı kullanılarak yapılan AFA sonucunda faktörler ve faktörlerle ilişkili maddeleri ortaya koyan bir ölçek modeli ortaya konmuştur. AFA sonucunda, toplam varyansın \% 75.85'ini açıklayan 2 faktör ve 17 maddeden oluşan bir yapı elde edilmiştir. Varyansın \%68.05'ini açıklayan ve "olumlu duygu bileşeni" olarak isimlendirilmiş birinci faktörde 11; varyansın \%7.79'unu açıklayan ve "olumsuz duygu bileşeni" olarak isimlendirilmiş ikinci faktörde 6 madde yer almıştır. DFA uygulanarak oluşturulan modelin doğruluğu test edilmiştir. Modelin değerlendirilmesinde ele alınan uyum indeks değerleri incelendiğinde, model yapısı ile elde edilen veriler arasında kabul edilebilir düzeyde uyum olduğu tespit edilmiştir. MYYTÖ madde analizi çalışmalarında madde-toplam korelasyonlarına bakılmıştır. Ölçeğin maddelerinin hem ölçmek istediği özelliği ölçmeye hizmet ettiği, hem de ölçülmek istenen özelliğe sahip olan ve olmayan bireyleri ayırt edebildiği bulgusu elde edilmiştir.

Güvenirlik çalışmaları için ölçeğe ait Cronbach alfa güvenirlik katsayıları değerleri incelenmiştir. Ölçeğin geneline ait güvenirlik katsayısı .97; birinci faktör için güvenirlik katsayısı .95 ve ikinci faktör için güvenirlik katsayısı .97 olarak hesaplanmıştır. Güvenirlik sonuçları incelendiğinde, hem genelde hem de faktörler düzeyinde ölçeğin güvenilir olduğu gözlemlenmiştir. Buna göre, ölçek maddelerinin ölçülmek istenen özelliği güvenilir şekilde ölçtüğü söylenebilir.

Çalışmada elde edilen bulgular değerlendirildiğinde, müzik yazılımlarına yönelik tutumları ölçmek amacıyla geliştirilen ölçeğin amacına uygun özelliklere sahip olduğu söylenebilir. Elde edilen ölçeğin, müzik öğrencilerinin müzik yazılımlarına yönelik tutumlarını belirleyebilmek için etkili bir veri toplama aracı olacağı düşünülmektedir. Müzik yazılımlarına yönelik tutumları belirlemeye yönelik hali hazırda bir ölçek olmaması, geliştirilen bu ölçeğin yapılacak çalışmalar için önemli bir boşluğu dolduracağ 1 düşünülmektedir. Sonuç olarak, bu çalışma sonucunda kabul edilebilir düzeyde geçerli ve güvenilir bir ölçek geliştirildiği ifade edilebilir. Ölçek uygulamasından alınacak yüksek puanların, müzik yazılımlarına yönelik tutumların olumlu yönde olduğunu göstereceği söylenebilir. Bu ölçek, çalışma grubu dışında kalmış olan diğer müzik öğrencilerinin, geçerlik ve güvenirlik çalışmaları yapıldıktan sonra da müzik öğretmenleri ve müzik bölümlerinde çalışan akademisyenler gibi farklı grupların müzik yazılımlarına yönelik tutumlarını belirlemede kullanılabilir. Geliştirilen ölçeğe ait geçerlik ve güvenirlik çalışmaları hem zaman hem de maddi imkanlar sebebiyle aynı çalışma grubu üzerinde gerçekleştirilmiştir. Gelecek çalışmalarda farklı çalışma grupları üzerinde, geliştirilen ölçeğin geçerlik ve güvenirlik değerleri test edilebilir. Konu ile ilgili araştırmacılar, müzik yazılımlarına yönelik eğilimlerin belirlenebileceği geniş kapsamlı ve çeşitli araştırmalar planlayabilirler. 


\section{Kaynakça}

Ahmetzade, E. (2013). Türk müziğinde temel nazari bilgiler konulu etkileşimli öğretim yazllımı. [Yayımlanmamış yüksek lisans tezi]. www.tez.gov.tr

Arslan, A. (2006). Bilgisayar destekli eğitim yapmaya ilişkin tutum ölçeği. Yüzüncü Yıl Üniversitesi Ĕgitim Fakültesi Dergisi, 3(2), 24-33. http://efdergi.yyu.edu.tr/dergiler.php?s=iii

Babacan, M. \& Babacan, E. (2011). Midi klavyenin okul şarkılarında kullanımına yönelik uygulama çalışması. Paper presented at the 5th Internationel Computer \& Instructional Technologies Symposium, Firat University, Elazı $\breve{g}, \quad$ September 2011. http://web.firat.edu.tr/icits2011/papers/27822.pdf

Bell, A. P. (2015). Can we afford these affordances? Garageband and the double-edged sword of the digital audio workstation. Action, Criticism, \& Theory for Music Education, 14(1), 44-65. http://act.maydaygroup.org/articles/Bell14_1.pdf

Beşer, U. (2010). Müzik eğitiminde teknoloji kullanımının müzik eğitimcileri açısından değerlendirilmesi. [Yayımlanmamış yüksek lisans tezi]. www.tez.gov.tr

Bollen, K. (1989). A new incremental fit index for general structural equation models. Sociological Methods And Research, 17(3). https://doi.org/10.1177/0049124189017003004

Brown, T. A. (2006). Confirmatory factor analysis: For applied research. Guilford Press.

Bryman, A. ve Cramer, D. (2001). Quantitative data analysis with SPSS release 10 for Windows. Routledge Press.

Byrne, B. M. (1998). Structural equation modeling with LISREL, PRELIS and SIMPLIS: Basic concepts, applications and programming. Lawrence Erlbaum Associates.

Cabi, E. (2016). Dijital teknolojiye yönelik tutum ölçeği. Kastamonu Eğitim Dergisi, 24(3), 875-890. https://kefdergi.kastamonu.edu.tr/index.php/Kefdergi/article/view/674

Çakırer, H. S. (2002). Türkiye'de müzik eğitiminde teknoloji. [Yayımlanmamış doktora tezi]. www.tez.gov.tr

Çetin, Ş. \& Çetin, F. (2019). Öğrenmeye yönelik tutum ölçeği geliştirme çalışması. Türk Eğitim Bilimleri Dergisi, 17(1), 140-157. https://dergipark.org.tr/tr/pub/tebd/issue/46309/537967

Çevik, B. D. \& Alkan, M. (2012). Müzik öğretmenliği bölümü öğrencilerinin teknoloji kullanımına yönelik görüşleri. Journal of Educational and Instructional Studies in The World, 2(1), 135141. http://www.wjeis.org/FileUpload/ds217232/File /20x.cevik.pdf

Dammers, R. J. (2012). Technology-based music classes in high schools in the United States. Bulletin of the Council for Research in Music Education, (194), 73-90. http://www.jstor.org/stable/10.5406/bulcouresmusedu.194.0073

Demirtaş, E. (2017). Müzik öğretmeni adaylarının öğretim materyali geliştirme aracı olarak ses kayıt ve düzenleme programlarının kullanılmasına yönelik görüşleri. [Yayımlanmamış yüksek lisans tezi]. Gazi Üniversitesi Eğitim Bilimleri Enstitüsü.

Diamantopoulos, A. \& Siguaw, J. A. (2000). Introducing LISREL. Sage Publications.

Ekici, G. \& Bahçeci, E. (2006). Öğretmen adaylarının bilgisayara yönelik tutumları ile bilgisayarla ilgili özyeterlik algılarının değerlendirilmesi üzerine bir çalışma. VII. Ulusal Fen Bilimleri ve Matematik Eğitimi Kongresi'nde sunulmuş bildiri, 7- 9 Eylül. Gazi Üniversitesi, Ankara. 
Eroğlu, T. \& Demirtaş, E. (2018). Ses kayıt ve düzenleme programlarının öğretim materyali geliştirme aracı olarak kullanılması: Bir ölçek geliştirme çalışması. Güzel Sanatlar Enstitüsü Dergisi, (41), 48-59. https://doi.org/10.32547/ataunigsed.455933

Field, A. (2005), Discovering statistics using SPSS. Sage Publications.

Güler, H., Şahinkayası, Y. \& Şahinkayası, H. (2017). İnternet ve mobil teknolojilerin yaygınlaşması: Firsatlar ve sinırlılıklar. Sosyal Bilimler Dergisi, 7(14), 186-207. https://doi.org/10.31834/kilissbd.341511

Jöreskog, K. G. \& Sörbom, D. (1993). LISREL 8: Structural equation modeling with the SIMPLIS command language. Scientific Software International Inc.

Juntunen, P. Ruokonen, I. \& Ruismäki, H. (2015). Music behind scores: Case study of learning improvisation with playback orchestra method. Journal of Computer Assisted Learning, 31(6), 582-591. https://doi.org/10.1111/jcal.12098

İnceoğlu, M. (2010). Tutum algı iletişim. Beykent Üniversitesi Yayınevi.

Kaiser, H. F. (1974). An index of factorial simplicity. Psychometrika, 39, 31-36. https://doi.org/10.1007/BF02291575

Kass, R. A. \& Tinsley, H. E. A. (1979). Factor analysis. Journal of Leisure Research, 11, 120-138. https://doi.org/10.1080/00222216.1979.11969385

Kenar, İ. (2012). Teknoloji ve derslerde teknoloji kullanımına yönelik veli tutum ölçeği geliştirilmesi ve tablet pc uygulaması. Eğitim Bilimleri Araşttrmaları Dergisi, 2(2), 123-139. https://www.pegem.net/dosyalar/dokuman/137932-20130521111330-2-2---08.pdf

Keskinkılıç, M. \& Özmen, E. (2018). Yazılım projelerinde yazılım geliştiricilerin yazılım süreç modellerini kullanım farkındalıkları. Akademi Sosyal Bilimler Dergisi, 5(15), 61-78. https://dergipark.org.tr/tr/pub/asbider/issue/41362/500096

Kline, P. (1994). An easy guide to factor analysis. Routledge Press.

Kline, R. B. (2010). Principles and practice of structural equation modeling. Guilford Press.

Koç, A. (2004). Günümüzde bilgisayar destekli yazllımların müzik eğitimine katklları. 1924-2004 Musiki Muallim Mektebinden Günümüze Müzik Öğretmeni Yetiştirme Sempozyumu'nda sunulmuş bildiri, Süleyman Demirel Üniversitesi, Nisan, Isparta.

Koldemir, S. (2008). Anadolu güzel sanatlar liselerinde bilgisayar destekli müzik eğitiminin kullanılabilme durumu. [Yayımlanmamış yüksek lisans tezi). www.tez.gov.tr

Ledger, T. (1999). Teacher knowledge and attitudes towards the utilization of assistive technology in educational settings. (Master Thesis). Longwood University. http://digitalcommons.longwood.edu/etd/182

Lehimler, E. (2012). Müzik öğretmeni yetiştiren kurumlarda bilgisayar derslerinde öğretilen müzik programlarının ve yazılımlarının piyano eğitimine katkılarının incelenmesi. [Yayımlanmamış yüksek lisans tezi). www.tez.gov.tr

Lehimler, E. (2019). The evaluation of music teacher candidates' awareness of music applications and software, their frequency of use and purpose of use. Journal of Education and Training Studies, 7(10), 99-107. https://doi.org/10.11114/jets.v7i10.4381

Likert, R. (1932). A technique for the measurement of attitudes. Archives of Psychology, 22, 5-55. https://legacy.voteview.com/pdf/Likert_1932.pdf

Miller, W. (2012). iTeaching and learning: Collegiate instruction incorporating mobile tablets. 


Library Technology
https://scholarworks.iupui.edu/bitstream/handle/1805/15630/Miller-2012-
iTeaching.pdf? sequence=1
iTeaching.pdf? sequence $=1$

Nunnally, J. C. (1978). Psychometric testing. McGraw-Hill.

Nunnally, J. C. \& Bernstein, I. (1994), Psychometric theory. McGraw-Hill.

Order, S. (2015). ICreate: Preliminary usability testing of apps for the music technology classroom. Journal of University Teaching \& Learning Practice, 12(4), 1-15. https://eric.ed.gov/?id=EJ1063831

Önder, O. \& Yıldız, G. (2015). Müzik uygulamalarında tablet bilgisayar (İpad) kullanımı. Süleyman Demirel Üniversitesi Güzel Sanatlar Fakültesi Dergisi, 15(15), 127-154. http://dergipark.ulakbim.gov.tr/sduarte/article/view/5000113571

Şen, Ü. S. (2011). Müzik öğretiminde bilgisayar destekli programlı ögretim yönteminin etkililiği. [Yayımlanmamış doktora tezi]. www.tez.gov.tr

Tavşancıl, E. (2014). Tutumların ölçülmesi ve SPSS ile veri analizi. Nobel Akademik Yayıncılık.

Thompson, B. (2004). Exploratory and confirmatory factor analysis: Understanding concepts and applications. American Psychological Association. https://doi.org/10.1037/10694-000

Thurstone, L. L. (1928). Attitudes can be measured. American Journal of Sociology, 33(4), 529-554. http://www.jstor.org/stable/2765691

Türk Dil Kurumu (2019). Türkçe sözlük. http://www.tdk.gov.tr

Van Laarhoven, T. \& Conderman, G. (2011). Integrating assistive technology into special education teacher preparation programs. Journal of Technology and Teacher Education, 19(4), 473497. https://eric.ed.gov/?id=EJ957113

Wise, S., Greenwood, J. \& Davis, N. (2011). Teachers' use of digital technology in secondary music education: Illustration of changing classrooms. British Journal of Music Education, 28(2), 117-134. http://journals.cambridge.org/abstract_S0265051711000039

Yavuz, S. (2005). Developing a technology attitude scale for pre-service chemistry teachers. The Turkish Online Journal of Educational Technology, 4(1), 17-25.

Yengin, A. (2014). Müzik teknolojilerinin örgün müzik ĕgitiminde kullanılma durumlarına ilişkin ögretmen görüşleri: Burdur ili örneği. [Yayımlanmamış yüksek lisans tezi). www.tez.gov.tr 